\title{
PREDICTIVE MODELS OF CHLOROPHYLL CONTENT IN SUGARCANE SEEDLINGS USING SPECTRAL IMAGES
}

\author{
Nelson Oliveros ${ }^{1}$, Rodolpho Tinini' ${ }^{2}$ Daniel dos S. Costa ${ }^{3}$, \\ Rodrigo Ramos ${ }^{4}$, Caio Wetterich ${ }^{5}$, Bárbara Teruel ${ }^{1 *}$
}

\begin{abstract}
${ }^{1 *}$ Corresponding author. School of Agricultural Engineering, University of Campinas/ Campinas - SP, Brazil. E-mail: barbara.teruel@feagri.unicamp.br| ORCID ID: https://orcid.org/0000-0002-5102-6716
\end{abstract}

KEYWORDS
non-destructive
methods,
chemometrics,
principal component
regression, partial
least squares
regression.

\begin{abstract}
Chlorophyll content is a widely used parameter for nutritional status diagnosis in sugarcane. This study aimed to develop a predictive model of chlorophyll content in sugarcane seedlings using spectral imagery analysis within the electromagnetic spectrum visible range. The experiment was carried out in a split-plot design, with two fertilization rates and three sugarcane cultivars. For chlorophyll analysis, 144 leaves were collected from seedlings. Chlorophyll contents were extracted and measured by SPAD-502 meter. Spectral images within the range of 480 to $710 \mathrm{~nm}$ were analyzed using reflectance, absorbance (white source), and fluorescence (source at 405 and $470 \mathrm{~nm}$ ) responses. Predictive models were developed using multivariate regression methods such as Principal Component Regression and Partial Least Squares Regression. We chose the best model through absorbance response using variable selection and the PLSR method (R2P $=0.718$ and RMSEP $=7.665$ ). The wavelengths of 480, 490, 500, 600, 630, and $640 \mathrm{~nm}$ were identified as the best for total chlorophyll content determination. The spectral image processing-based method can provide a chlorophyll measurement equivalent to SPAD, with the advantage of having a higher spatial coverage over the entire leaf area. Besides, it can also support automation of the chlorophyll measurement in greenhouses.
\end{abstract}

\section{INTRODUCTION}

Brazil is the largest sugarcane grower worldwide $(40 \%)$ and the second-largest ethanol producer (CONAB, 2019). As the sugar-energy industry has grown sustainably, new seedling production techniques must be studied to boost production. An example of this is sugarcane planting using pre-sprouted seedlings (PSS). Such a technique improves plant physiological traits and speeds up the production process, associating phytosanitary quality, plant vigor, and planting uniformity (Almeida et al., 2020; Libardi et al., 2018; Aquino et al., 2018).

Aiming to maintain quality standards and aid decision-making, producers have used several biometric measurements of sugarcane as indicators of plant vigor, nutritive status, and seedling quality (Garcia et al., 2020; Oliver \& Silva, 2018). Seedling chlorophyll contents provide subsidies for fertilization, especially pre-sprouted seedlings. In this regard, the Soil Plant Analysis Development (SPAD) portable chlorophyll meter has been generally used (Yang et al., 2019; Radhamani et al., 2016; Silva et al., 2016). However, SPAD has some limitations since measurements are made on a small area of leaves, and factors such as leaf thickness, phenological stage, plant genotype, and shading may affect accuracy (Afonso et al., 2018).

Chlorophyll content measurement using spectral image processing covers a larger spatial area and is more accurate compared to the SPAD method. These advantages improve plant nutritional status diagnosis due to an increased number of samples for decision-making. Chlorophyll content has been assessed using spectral responses in several crops such as cucumber and corn, and

\footnotetext{
${ }^{2}$ Agricultural Science Institute, Federal University of Minas Gerais/ Montes Claros - MG, Brazil.

${ }^{3}$ College of Agricultural and Environmental Engineering, Federal University of the São Francisco Valley/ Juazeiro - BA, Brazil.

${ }^{4}$ College of Electrical Engineering, Federal University of the São Francisco Valley/ Juazeiro - BA, Brazil.

${ }^{5}$ Federal Institute of Triangulo Mineiro, Campus Uberaba/ Uberaba - MG, Brazil
}

Area Editor: Lucas Rios do Amaral

Received in: 5-11-2020

Accepted in: 5-19-2021 
have generated good results (Liu et al., 2017; Wu et al., 2016; Xiaobo et al., 2011).

Developing a predictive model of chlorophyll content based on visible region images will allow in vivo diagnosis of sugarcane PSS nutritional status in greenhouses and will serve as a basis for non-invasive monitoring of chlorophyll distribution. This will require a smaller dataset and hence less computational processing capacity, decreasing costs when compared to the commercially available systems.

This study aimed to develop a predictive model of chlorophyll content in sugarcane seedlings by analyzing spectral images within the electromagnetic spectrum visible region. Therefore, we implemented an experimental design for the distribution of seedlings in sub-irrigation rows inside a greenhouse. A spectral image analysis algorithm was then developed and different chemometric methods tested to predict chlorophyll content. Finally, regression metrics were used to choose the best model.

\section{MATERIAL AND METHODS}

Sugarcane seedlings were grown in a greenhouse located at the School of Agricultural Engineering (FEAGRI) of the University of Campinas (UNICAMP) in

Table 1

\begin{tabular}{|l|l|l|l|l|l|}
\hline P1 & P2 & P3 & P4 & P5 & P6 \\
\hline P7 & P8 & P9 & P10 & P11 & P12 \\
\hline P13 & P14 & P15 & P16 & P17 & P18 \\
\hline
\end{tabular}

Table 3
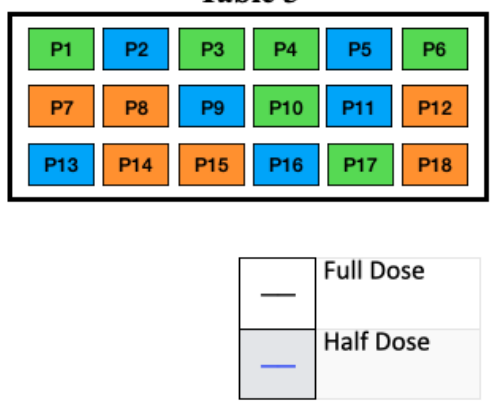

the city of Campinas - São Paulo State, Brazil (22 $48^{\circ}$ '57' S, $\left.47^{\circ} 03^{\prime} 33^{\prime \prime} \mathrm{W}\right)$, from August 16 to September 15 in 2017. In the greenhouse, four sub-irrigation rows were used in a pre-sprouted seedlings (PSS) system. In each sub-irrigation row, specific fertilizer doses were applied through fertigation. The fertigation system was equipped with an on/off fluid control that acts directly on the pump that applies nutrient solution.

\section{Experimental design}

In the experiment, we used sugarcane (Saccharum officinarum) seedlings of three commercial cultivars (IAC91-1099, IACSP95-5000, and IACSP95-5094), which are developed in the Agronomic Institute of Campinas (IAC). The experiment was carried out in a fully randomized split-plot design and a $2 \times 3$ factorial scheme, with two fertilization levels (full and half dose) with 2 repetitions each, and three sugarcane cultivars (the above mentioned) with 6 repetitions each. After randomization, each sampled plot in the table was coded as Px (with $\mathrm{x}$ ranging from 1 to 18), assigning a cultivar to each plot. Full dose refers to $60 \%$ of the total dose recommended to fullygrown sugarcane in the field, while half dose refers to $30 \%$ of the fertilization dose recommended for sugarcane in field conditions (Figure 1).

Table 2

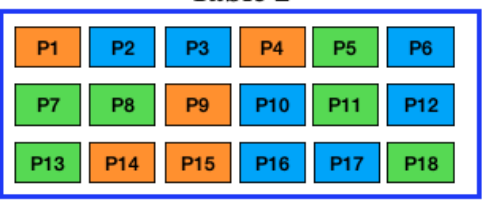

Table 4

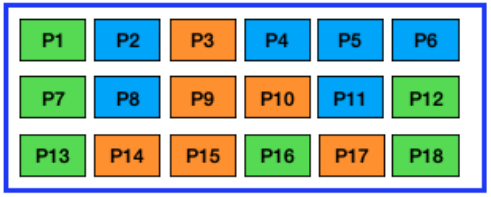

IAC 5000

IAC 5094

IAC 1099

FIGURE 1. Experimental design composed of two fertilization levels (full dose and half dose) and two repetitions (two irrigation rows, or table, for each level).

Sampling was carried out weekly throughout the four weeks seedlings remained in the greenhouse. Irrigation was interrupted in the last week to induce water stress and obtain spectral variations in the chemometric modeling of chlorophyll contents.

Three leaf samples were randomly taken from each row or table plot (only one cultivar) for analysis by the "leaf +1 " diagnostic method, as recommended by Garcia et al., 2020. The analysis was performed for each cultivar in each fertigation dose, resulting in 36 samples per day and 144 samples throughout the experiment.

In the laboratory, 30-mg samples were taken from the middle third of leaves to obtain the following measurements: (1) SPAD chlorophyll content (in triplicate), (2) spectral images, and (3) reference chlorophyll content.

\section{Chlorophyll measurements}

Images were acquired to obtain minimally altered leaf samples, before reference measurement. Two chlorophyll measuring methods were used: a laboratory analytical method by chlorophyll extraction (Hiscox \& Israelstam, 1979) and the SPAD-502 meter [at two bands: 400 to $500 \mathrm{~nm}$ (blue) and 600 to $700 \mathrm{~nm}$ (red), with an accuracy of \pm 1.0 SPAD units, supplied by Konica Minolta Sensing Americas, USA). First, SPAD measurements were taken, followed by image acquisition, and finally the analytical method as it is a destructive technique.

\section{Spectral image acquisition}

Spectral images were acquired using a reflectance and fluorescence imaging system. The system is composed of the components (Figure 2) described below: 
(a) A scientific CCD camera (mvBlueFox-223 G, Matrix Vision, with $1360 \times 1024$ pixels) with activated sensor area and 25-mm bandpass optical filters with $10 \mathrm{~nm}$ resolution (Edmund Optics, Norway), mounted in a motorized filter wheel (FW102C, Thorlabs, USA) with six filter positions each. The set consisted of 24 optical filters covering the electromagnetic spectrum between 480 and $710 \mathrm{~nm}$ (from the end of the blue band to the beginning of the red band within the visible electromagnetic spectrum); (b) A lightning system support structure composed of an in-lab built "black box" for external light insulation and black anodized support to place samples;

(c) A high-power LED lighting system with three different colors (white, $405 \mathrm{~nm}$, and $470 \mathrm{~nm}$ ) as an excitation source function for the acquisition of reflectance, absorbance, and fluorescence spectral images;

(d) A computer with supervision and control software to adjust CCD camera gain and exposure time, and then inspect and save images.

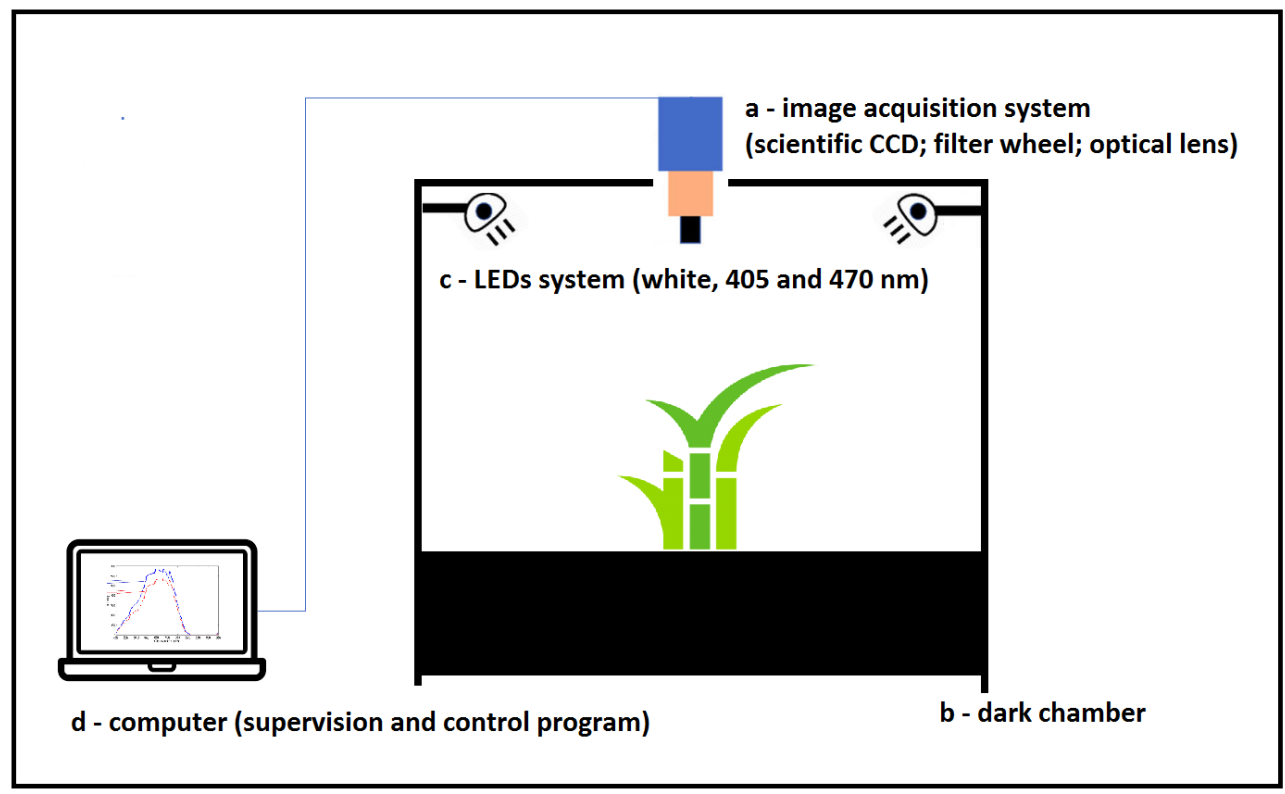

FIGURE 2. Reflectance and fluorescence imaging system setup.

To acquire spectral images, leaf samples were placed in the dark chamber $30 \mathrm{~cm}$ apart from each other and the CCD. The process was based on the method described by Wetterich et. al (2016), which consisted of setting up the CCD with a maximum gain $(30 \mathrm{~dB})$, changing exposure time, and capturing images at each wavelength, repeating the procedure for each excitation source.

Leaf samples (30 $\mathrm{mg}$ of middle third of leaves each) already measured by SPAD and the reference method were placed in a dark chamber. Reflectance images were firstly acquired using white light excitation and acquiring images at all wavelengths. Afterwards, the same procedure was employed for fluorescence images, changing excitation sources for 405 and $470 \mathrm{~nm}$. Yet for absorbance images, reflectance images were transformed using [eq. (1)], wherein $\mathrm{A}$ is the absorbance value and $\mathrm{R}$ the reflectance value.

$$
A=-\log \left(\frac{1}{R}\right)
$$

\section{Reference measurements of chlorophyll}

Reference measurements of chlorophyll contents were carried out after image acquisition. For pigment extraction and chlorophyll quantification, the protocol of Hiscox \& Israelstam (1979) was followed and modified for $30 \mathrm{mg}$ leaf tissue. Leaf samples were disposed individually in 3-mL DMSO (dimethyl sulfoxide) and allocated to a stirring table for $24 \mathrm{~h}$ in the dark. Then, the supernatant of each sample was removed and absorbance measured in a spectrophotometer. The pigment contents were calculated as indicated in eqs (2)-(4), wherein $A_{W L}$ represents the absorbance at WL wavelength. After pigment quantification, the content of each chlorophyll (Chl a, Chl $\mathrm{b}, \mathrm{Chl} \mathrm{a}+\mathrm{b}$ ) was converted to $\mathrm{mg} \mathrm{cm}^{-2}$ by using digital image analysis to estimate the area of each leaf sample.

$$
\begin{aligned}
& \operatorname{Chla}\left(g l^{-1}\right)=0.0127 A_{663}-0.00269 A_{645} \\
& \operatorname{Chlb}\left(g l^{-1}\right)=0.0229 A_{645}-0.00468 A_{663} \\
& \operatorname{Chla}+b\left(g l^{-1}\right)=0.0202 A_{645}-0.00802 A_{663}
\end{aligned}
$$

\section{Spectral image processing}

An image processing algorithm was implemented to extract information for predictive model development. Procedures included image normalization using CCD (Charged Couple Device) camera response curve, segmentation using reference mask images, ROI (Region of Interest) pixels organization in a dataset matrix, and spectral matrix creation by average spectra calculation.

Images were normalized following the procedure described by Wetterich et. al (2016). This normalization is needed since the exposure time of each sample and wavelengths are not identical. The first step was to obtain the spectral function (Equation 5) from the product of the CCD spectral sensitivity curve $\left(T_{c}\right)$ and the transmission rate of the optical bandpass filter used $\left(\mathrm{T}_{\mathrm{f}}\right)$. Once the $E$ function was obtained, spectral information at a specific 
wavelength (I $(\lambda)$ could be eliminated from Equation 6 . Finally, after the new images were acquired, $I_{s}(\lambda)$, the different exposure times of the CCD camera were eliminated by multiplying these new images by the ratio between minimum exposure time $(\min )$ and exposure time at a given wavelength $(\mathrm{t}(\lambda)$ ) (Equation 7). Further details about these procedures can be found in Wetterich et. al (2016).

$$
\begin{aligned}
& E=T_{c} \times T_{f} \\
& I_{s}(\lambda)=\frac{I(\lambda)}{E_{n}(\lambda)} \\
& I_{\text {final }}(\lambda)=I_{s}(\lambda) \times \frac{t_{\text {min }}}{t(\lambda)}
\end{aligned}
$$

Where:

$E$ is the final response curve after the multiplication of response curves;

$T_{c}$ is the CCD response curve (obtained from camera datasheet);

$T_{f}$ is the optical filter response curve;

$I_{s}$ represents the image after spectral information elimination;

$I$ is the original image;

$t_{\min }$ is the minimum exposure time (ms);

$t$ is the exposure time at each wavelength, and

$\lambda$ is the wavelength (nm).

After normalization, the algorithm performed a supervised image segmentation for background elimination. During the process, an image was acquired with a white excitation source and no optical filters. The image was converted into a binary mask using a histogram-based threshold for further application in each normalized image (all wavelengths), resulting in a segmented image.

The next step was to automatically find the minimum ROI within samples using the area given in pixels. Using this area, the algorithm applied an average mask onto the image to estimate average reflectance/fluorescence response for each excitation source, resulting in a matrix of dimensions 36 (leaf samples or ROIs) x 21 (wavelengths) for each excitation source, i.e., each spectral response. For absorbance, as mentioned above, a mathematical conversion based on [eq (1)] was used.

\section{Development of prediction models}

In this study, chemometric predictive models were developed using the multivariate regression methods of
Partial Least Squares Regression (PLSR) and Principal Components Regression (PCR). Their advantage is to model several predictor variables (reflectance, absorbance, and fluorescence of spectral images at different wavelengths), considering synergy among them to predict a variable response (chlorophyll content).

The first set of samples (2/3) was used for calibration and cross-validation, and the second (1/3) for prediction. Full cross-validation was used to determine the optimal number of latent variables (LV) or principal components (PC) in the calibration models. To identify the outlier, the leverage and Student's $t$ residual of each sample were quantified and evaluated as decision-making criteria.

Variable selection based on correlation spectrum was also evaluated by testing different correlation thresholds. To select the best calibration models, the accumulated variance was firstly evaluated as a function of the number of factors selected, aiming to use the smallest number of factors with more variance. Afterwards, the root mean square error of calibration (RMSEC), root mean square error of cross-validation (RMSECV), determination coefficient of calibration $\left(\mathrm{R}^{2} \mathrm{C}\right)$, and determination coefficient of cross-validation $\left(\mathrm{R}^{2} \mathrm{CV}\right)$ were the statistical parameters used to evaluate each model performance. The models with fewer factors and better RMSE and $\mathrm{R}^{2}$ values were selected as the best for each method (PLSR and PCR). Thereafter, the best calibration models were used to predict the dataset of independent samples. The models were validated using RMSECV and RMSEP to quantify their precision, and $\mathrm{R}^{2} \mathrm{C}$ and $\mathrm{R}^{2} \mathrm{P}$ to quantify their fit.

\section{RESULTS AND DISCUSSION}

\section{Chlorophyll content}

Figure 3 shows the chlorophyll content responses of each cultivar and their standard deviation. The results obtained for IAC 5000 corroborate those of Boaretto et al. (2014), who tested two soil water stress levels. Cultivar did not affect the range of chlorophyll contents, which had similar means and high standard deviations in all cases. Both fertigation doses (Figure 3A and 3B) produced similar and indistinguishable ranges of chlorophyll content, also influenced by high standard deviations.

Since physiological development time is a factor in the variation in chlorophyll content, the same analysis was applied for three weeks and under stress conditions (Figure 3C). Such descriptive statistics reinforce that cultivar and fertigation rate variation factors do not affect chlorophyll content. However, physiological development time and stress have a greater influence on chlorophyll contents. 

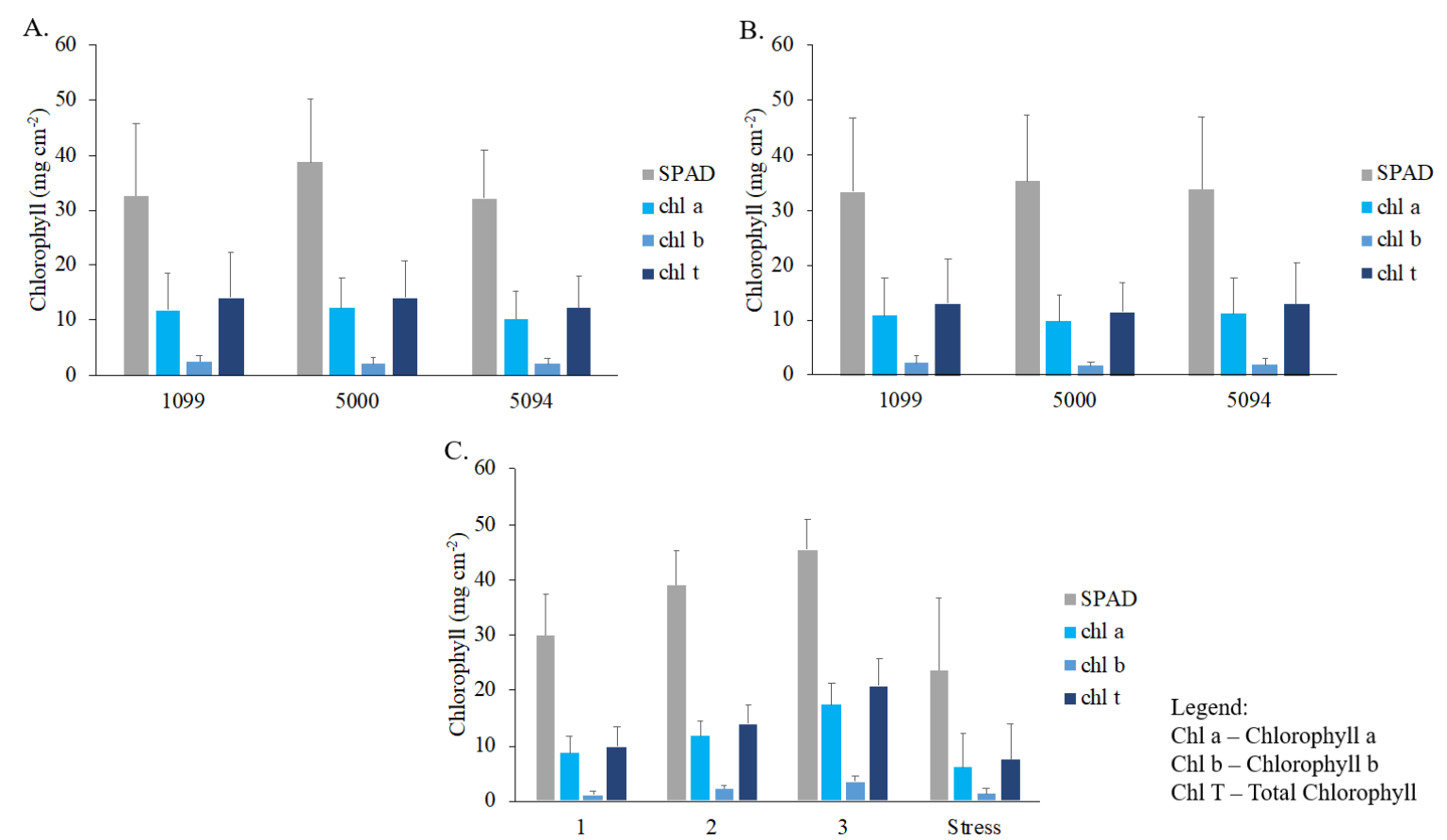

FIGURE 3. Characterization of chlorophyll measurements separated by cultivar for A) full-dose treatment, B) half-dose treatment, and C) development time.

A close relationship was found between chlorophyll contents using the analytical method and the portable chlorophyll meter (SPAD) (Figure 4). This relationship was better expressed by a linear model in a wide range of chlorophyll (Chl) contents, although most authors agree that nonlinear models are more suitable for the relationship between portable measurements and real $\mathrm{Chl}$ contents (Yang et al., 2019; Kalaji et al., 2017; Silva et al., 2016; Rigon et al., 2012). This may be related to Chl uniform distribution and absence of multiple spreading associated with leaf thickness, as the leaves used were from young seedlings (Marenco et al., 2009).

Determination coefficients were $0.76,0.57$, and 0.77

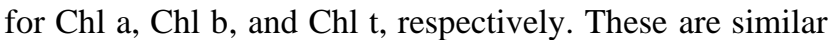
to those reported by Jangpromma et al. (2012) for sugarcane under water stress. These authors, however, performed a separate correlation analysis for each treatment. In turn, we intended to create a functional predictive model for a wide range of $\mathrm{Chl}$ contents. 

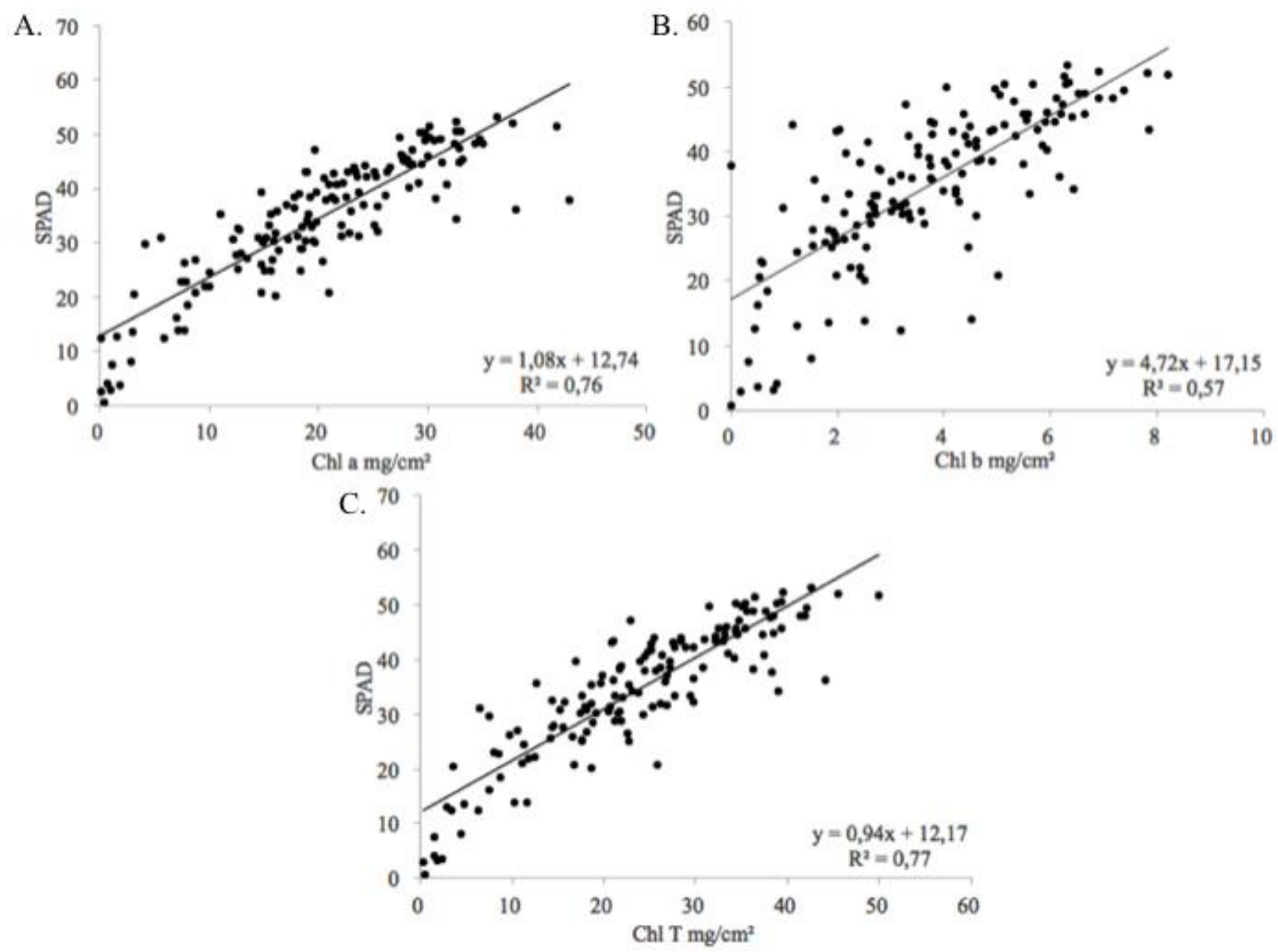

FIGURE 4. Relationship between portable SPAD chlorophyll meter readings and the contents of A) chlorophyll a, B) chlorophyll $\mathrm{b}$, and C) total chlorophyll using the laboratory reference method.

The SPAD Chl meter is designed for leaf chlorophyll quantification and has proven to be precise for fast and nondestructive measures of Chl content in several crop species (Beresel et al., 2017; Riccardi et al., 2014; Sala et al., 2013; Rigon et al., 2012). However, leaf chlorophyll contents are affected by environmental factors, leaf traits, and crop nutritional conditions (Xiong et al., 2015). Given these influences and to increase its accuracy, the SPAD must be calibrated for each cultivar and species. Furthermore, as it is a handheld and portable device, it requires a sampling procedure before measuring chlorophyll contents in sugarcane seedlings.

\section{Spectral image processing}

Mean spectra were calculated by exploratory analysis for each spectral response (reflectance, absorbance, and fluorescence), and the first inspection implemented to identify key response regions for each optical property (FIGURE 5).

When examining the average reflectance spectra in Figure 5A, we can point out a high reflectance region near 550 and $620 \mathrm{~nm}$ wavelengths, which are highly correlated with chlorophyll contents (Phetpan et al., 2018). By evaluating the average absorbance spectra (Figure 5B), we can note absorption at the wavelengths of 490, 570, 580, 590, and 600 $\mathrm{nm}$. Also, in Figure 5C, we can see a satisfactory fluorescence response for excitation at $405 \mathrm{~nm}$, while for excitation at 470 $\mathrm{nm}$ (Figure 5D) there was a significantly larger response for the range of 480 to $580 \mathrm{~nm}$. However, this region is associated with a reflection from the $470 \mathrm{~nm}$ excitation source. Since red band fluorescence emission overlaps the long-wavelength range of the chlorophyll absorption spectrum, strong reabsorption occurs (Lu \& Lu, 2020). 


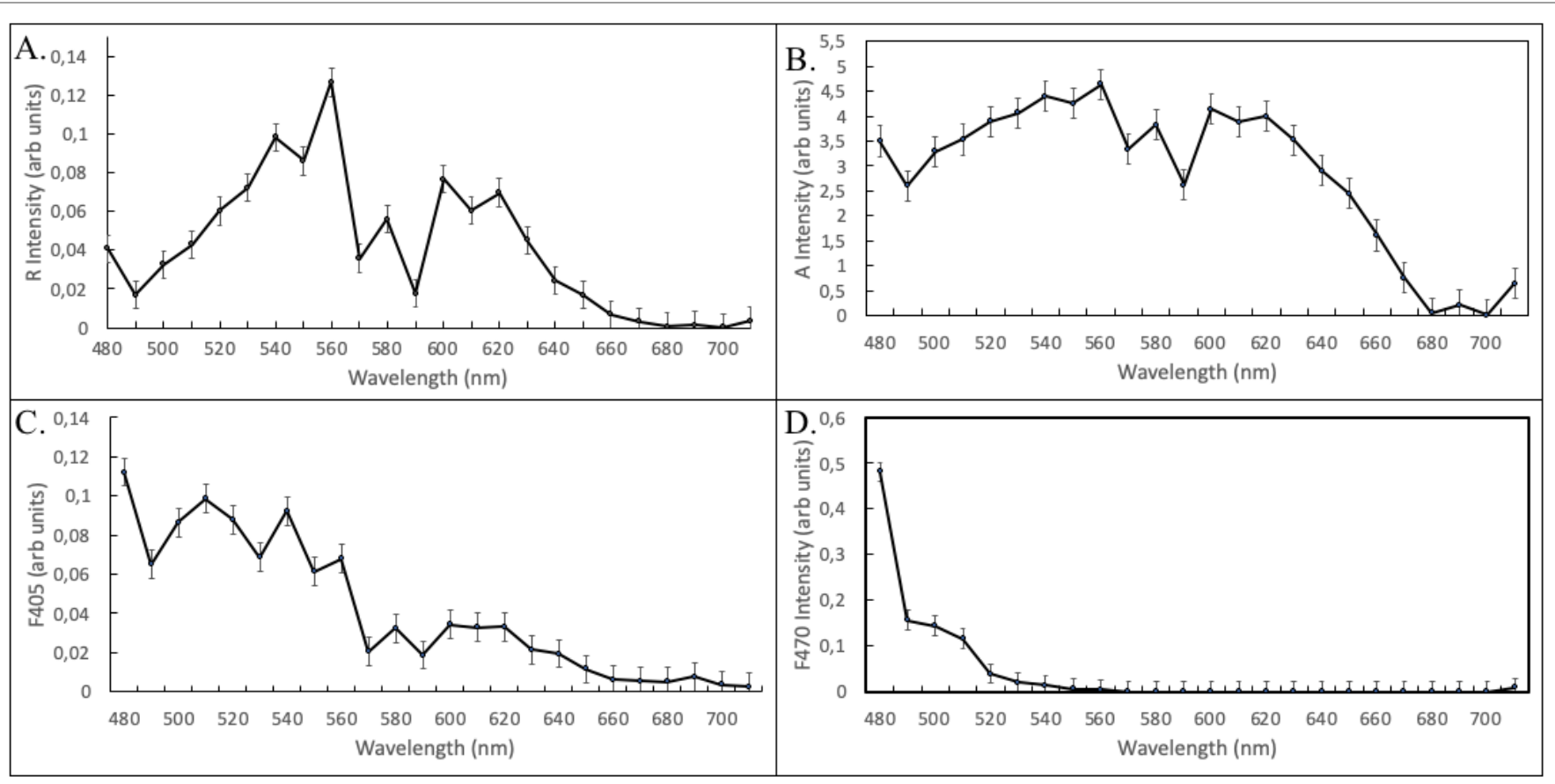

FIGURE 5. Mean spectral response for A) Reflectance, B) Absorbance, C) Fluorescence 405 nm, and D) Fluorescence 470 nm.

\section{Prediction models}

The variable selection method based on correlation spectrum was also evaluated for the model development. It only improved model performance for absorbance response, wherein the threshold was set at 0.3 (absolute value of correlation coefficient). Furthermore, all spectral regions with lower absolute values of correlation coefficient were not considered in the model development (FIGURE 6). To select the best model, the predictive capacity was assessed using RMSEP (root mean square error of prediction) for accuracy and $\mathrm{R}^{2} \mathrm{P}$ (determination coefficient of prediction) for fit (TABLE 1).

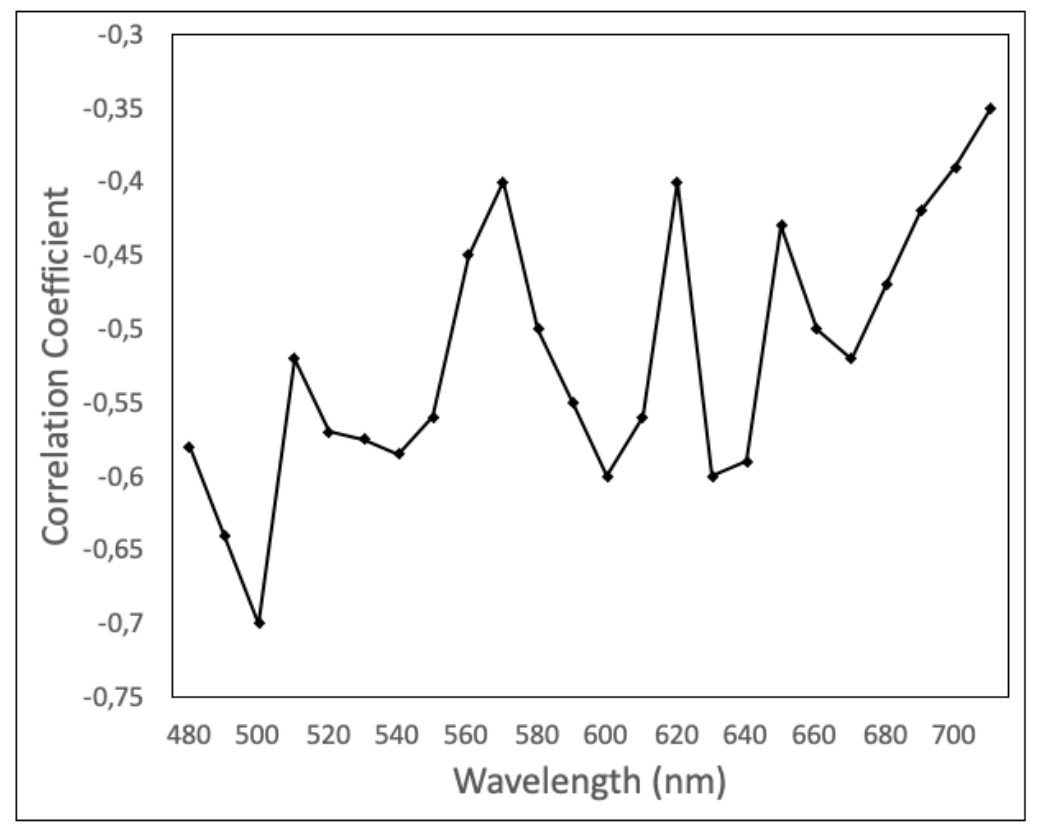

FIGURE 6. Correlation spectrum for total chlorophyll content in the absorbance analysis. 
TABLE 1. Performance of Principal Component Regression (PCR) and Partial Least Squares Regression (PLSR) models for prediction of total chlorophyll in each excitation source evaluated.

\begin{tabular}{llllll}
\hline Method & LVs/PCs & $\mathrm{R}^{2} \mathrm{C}$ & RMSECV & $\mathrm{R}^{2} \mathrm{P}$ & RMSEP \\
\hline
\end{tabular}

Total chlorophyll prediction using Reflectance Response

$\begin{array}{llllll}\text { PLSR } & 11 & 0.858 & 7.420 & 0.630 & 8.525 \\ \text { PCR } & 16 & 0.859 & 7.309 & 0.638 & 8.584\end{array}$

Total chlorophyll prediction using Absorbance Response

$\begin{array}{llllll}\text { PLSR } & 11 & 0.861 & 7.446 & 0.718 & 7.665 \\ \text { PCR } & 18 & 0.859 & 7.413 & 0.703 & 7.585\end{array}$

Total chlorophyll prediction using $405 \mathrm{~nm}$ Fluorescence Response

$\begin{array}{llllll}\text { PLSR } & 4 & 0.884 & 5.385 & 0.626 & 8.142 \\ \text { PCR } & 4 & 0.884 & 5.384 & 0.442 & 9.584\end{array}$

Total chlorophyll prediction using $470 \mathrm{~nm}$ Fluorescence Response

$\begin{array}{llllll}\text { PLSR } & 7 & 0.439 & 10.781 & 0.241 & 11.180 \\ \text { PCR } & 8 & 0.399 & 10.740 & 0.245 & 11.010\end{array}$

Legend: PCR - Principal Component Regression; PLSR - Partial Least Squares Regression; $\mathrm{R}^{2} \mathrm{C}$ - coefficient of determination of calibration; RMSECV - root mean square error of cross-validation; $\mathrm{R}^{2} \mathrm{P}$ - coefficient of determination of prediction; RMSEP - root mean square error of prediction.

The correlation spectrum clearly shows an inversely proportional relationship between spectral response and chlorophyll content, with the entire spectrum in the negative region (FIGURE 6). The regions (spectral signatures) with the highest correlation values were 480, 490, 500, 600, 630, and $640 \mathrm{~nm}$. Jay et al. (2017) reported that chlorophyll pigments have the highest absorbance peaks within the blue (428 to $453 \mathrm{~nm}$ ) and red (around 641 and $661 \mathrm{~nm}$ ) regions. We also observed higher correlation values for spectra near the blue (480 to $500 \mathrm{~nm}$ ) and red (640 to $660 \mathrm{~nm}$ ) regions. The spectral region beyond $650 \mathrm{~nm}$ has the lowest correlation coefficients, which is because relatively low chlorophyll contents are enough to saturate absorbance in the red region (Croft et al., 2015).

Table 1 shows that the best predictive models resulted from absorbance analysis with higher $\mathrm{R}^{2} \mathrm{P}$ (i.e., better fit) and lower RMSEP (i.e., better accuracy). The best model was selected based on the number of latent variables or principal components. Such criteria were used to reduce model complexity since $R^{2} C$ and $R^{2} P$ values were quite similar for both methods. In short, the best model obtained in this study were selected from absorbance analysis through variable selection and the PLSR method.

Consequently, the absorbance based predictive model presented a determination coefficient value with the analytical method $\left(R^{2}=0.72\right)$ close to that presented by the SPAD sensor $\left(R^{2}=0.77\right)$. Based on these results, we can conclude that it is possible to implement the VIS absorbance based predictive model working with a similar performance to the SPAD meter.

The model obtained in our study performed better than those from other studies wherein hyperspectral imaging and multivariate analysis were used (Wu et al., 2016) or even with the use of more sophisticated multivariate regression methods and a broader electromagnetic spectrum region (Martins et al., 2021).
Croft et al. (2015) assessed sugarcane chlorophyll content using hyperspectral images with a high determination coefficient (0.97) but did not assess the infrared region, which provided less spectral information than ours. However, they identified seven optimal bands $(495 \mathrm{~nm}, 555 \mathrm{~nm}, 655 \mathrm{~nm}, 675 \mathrm{~nm}, 705 \mathrm{~nm}, 915 \mathrm{~nm}$, and 985 $\mathrm{nm}$ ), which is consistent with our study where $560 \mathrm{~nm}$ was the region of highest absorbance in sugarcane chlorophyll.

Therefore, the method based on spectral image processing may provide a chlorophyll measurement equivalent to that of SPAD, with the advantage of covering the entire leaf area, thus enabling an automated chlorophyll measurement technique.

\section{CONCLUSIONS}

According to our results, the best model to predict total chlorophyll content was obtained with absorbance response in spectral images within the visible spectrum, using variable selection and the PLSR method. The 480, 490, 500, 600, 630, and $640 \mathrm{~nm}$ wavelengths were identified as spectral signatures for total chlorophyll content. Lastly, the spectral image processing-based method can provide a chlorophyll measurement equivalent to that of SPAD, with the advantage of covering the entire leaf area, enabling an automated chlorophyll measurement method.

\section{REFERENCES}

Afonso S, Arrobas M, Ferreira IQ, Rodrigues MA (2018) Assessing the potential use of two portable chlorophyll meters in diagnosing the nutritional status of plants. Journal of plant nutrition 41(2):261-271. DOI: https://doi.org/10.1080/01904167.2017.1385798 
Almeida NLA, Guiselini C, Menezes D, Cordeiro J, José JF, Pandorfi H (2020) Growth of pre-sprouted sugarcane seedlings submitted to supplementary lighting. Revista Brasileira de Engenharia Agrícola e Ambiental 24(3):194199. DOI: https://doi.org/10.1590/1807-

1929/agriambi.v24n3p194-199

Aquino GS, Dos Santos JS, Diniz TG, Medina CC, Rosseto R, Moreira A (2018) Development of presprouted seedlings (PSS) of sugarcane under different amounts of filter cake and application modes. Ciências Agrárias 39(5):1899-1908. DOI:

http://dx.doi.org/10.5433/1679-0359.2018v39n5p1899

Beresel JP, Rischbeck P, Hu Y, Kipp S, Hu Y, Barmeier G, Mistele B (2017) Use of a digital camera as alternative method for non-destructive detection of the leaf chlorophyll content and the nitrogen nutrition status in wheat. Computers and Electronics in Agriculture 140:2533. DOI: https://doi.org/10.1016/j.compag.2017.05.032

Boaretto LF, Carvalho, G, Borgo L, CresteS, Landell MG, Mazzafera P, Azevedo RA (2014) Water stress reveals differential antioxidant responses of tolerant and nontolerant sugarcane genotypes. Plant Physiology and Biochemistry 74:165-175. DOI: https://doi.org/10.1016/j.plaphy.2013.11.016

CONAB - Companhia Nacional de Abastecimento (2019) Acompanhamento da safra brasileira cana-de-açúcar. Brasília, CONAB, 77p.

Croft H, Chen JM, Zhang Y, Simic A, Noland TL, Nesbitt N, Arabian J (2015) Evaluating leaf chlorophyll content prediction from multispectral remote sensing data within a physically based modelling framework. ISPRS Journal of Photogrammetry and Remote Sensing 102:85-95. DOI: https://doi.org/10.1016/j.isprsjprs.2015.01.008

Garcia A, Crusciol, CAC, McCray, JM, Nascimento CAC, Martello JM, Siqueira GF, Tarumoto MB. (2020) Magnesium as a Promoter of Technological Quality in Sugarcane. Journal Soil Science Plant Nutrition 20:19-30. DOI: https://doi.org/10.1007/s42729-019-00096-X

Hiscox JD, Israelstam GF (1979) A Method for Extraction of Chlorophyll from Leaf Tissue without Maceration. Canadian Journal of Botany 57:1332-1334. DOI: http://dx.doi.org/10.1139/b79-163

Jangpromma N, Thammasirirak S, Jaisil P, Songsri P (2012) Effects of drought and recovery from drought stress on above ground and root growth, and water use efficiency in sugarcane (Saccharum officinarumL.). Australian Journal Crop Science 6(8):1298-1304.

Jay S, Gorreta N, Morel J, Maupas F, Bendoula R, Rabatel G, Dutartre D, Comar A, Baret F (2017) Estimating leaf chlorophyll content in sugar beet canopies using millimeter- to centimeter-scale reflectance imagery. Remote Sensing of Environment 198:173-186. DOI: https://doi.org/10.1016/j.rse.2017.06.008

Kalaji A, Dąbrowski P, Cetner M, Samborska I, Łukasik I, Brestic M, Zivcak M, Tomasz H, Mojski J, Kociel H, Panchal BM (2017) A comparison between different chlorophyll content meters under nutrient deficiency conditions. Journal of Plant Nutrition 40:1024-1034. DOI: https://doi.org/10.1080/01904167.2016.1263323
Libardi LP, De Faria RT, Dalri AB, Rolim GS, Palaretti LF (2018) High Precision Weighing Lysimeters for Evapotranspiration Measurements of Sugarcane PreSprouted Plantlets. Engenharia Agrícola 38:202-216. DOI: https://doi.org/10.1590/1809-4430-eng.agric.v38n2p208$216 / 2018$

Liu B, Shen W, Yue Y, Tong O, Zhang B (2017) Combining spatial and spectral information to estimate chlorophyll contents of crop leaves with a field imaging spectroscopy system. Precision Agriculture 18:491-506. DOI: https://doi.org/10.1007/s11119-016-9466-5

Lu, Y; Lu, R. (2020). Enhancing chlorophyll fluorescence imaging under structured illumination with automatic vignetting correction for detection of chilling injury in cucumbers. Computers and Electronics in Agriculture, 168: 105145. DOI:

https://doi.org/10.1016/j.compag.2019.105145

Silva D, Anjos L, Brito-Rocha E, Dalmolin AC, Mielke M (2016) Calibration of a multi-species model for chlorophyll estimation in seedlings of Neotropical tree species using hand-held leaf absorbance meters and spectral reflectance. iForest - Biogeosciences and Forestry 9:829-834. DOI: https://doi.org/10.3832/ifor1785-009

Marenco R, Antezana-Vera S, Nascimento H (2009) Relationship between specific leaf area, leaf thickness, leaf water content and SPAD-502 readings in six Amazonian tree species. Photosynthetica 47:184-190. DOI: https://doi.org/10.1007/s11099-009-0031-6

Martins JA, Fiorio PR, Barros PPS, Demattê JAM, Molin JP, Cantarella H, Neale CMU (2021) Potential use of hyperspectral data to monitor sugarcane nitrogen status. Acta Scientiarum. Agronomy 43:1-13. DOI: http://dx.doi.org/10.4025/actasciagron.v43i1.47632

Phetpan K, Udompetaikul V, Sirisomboon P (2018) An online visible and near-infrared spectroscopic technique for the real-time evaluation of the soluble solids content of sugarcane billets on an elevator conveyor. Computers and Electronics in Agriculture 154:460-466. DOI: https://doi.org/10.1016/j.compag.2018.09.033

Radhamani R, Kannan R, Rakkiyappan P (2016) Leaf Chlorophyll Meter Readings as an Indicator for Sugarcane Yield Under Iron Deficient Typic Haplustert. Sugar Tech 18:61-66. DOI: https://doi.org/10.1007/s12355-014-0363-9

Riccardi M, Mele G, Pulvento C, Lavini A, d'Andria R, Jacobsen SE (2014) Non-destructive evaluation of chlorophyll content in quinoa and amaranth leaves by simple and multiple regression analysis of RGB image components. Photosynthesis Research 120:263-272. DOI: https://doi.org/10.1007/s11120-014-9970-2

Rigon JP, Beltrao NE, Capuani C, Brito N, Silva FV (2012) Non-destructive analysis of photosynthetic pigments in leaves of Sesamum indicum (L.). Revista Brasileira de Engenharia Agrícola e Ambiental 16:258-261. DOI: http://dx.doi.org/10.1590/S1415-43662012000300004

Oliver R, Silva M (2018) Interaction between diazotrophic bacteria and $\mathrm{N}$-fertilizer doses on sugarcane crop. Journal of Plant Nutrition 41:722-736. DOI:

https://doi.org/10.1080/01904167.2018.1425436 
Sala F, Boldea M, Geren I (2013) Spectral imaging in the evaluation of the chlorophyll content in wheat. Research Journal of Agricultural Science 45:259-267. DOI:

https://doi.org/10.1063/1.4912898

Wetterich CB, Neves RF, Belasque J, Marcassa LG (2016) Detection of Citrus Canker and Huanglongbing Using Fluorescence Imaging Spectroscopy and Support Vector Machine Technique. Applied Optics 55:400 - 407. DOI: https://doi.org/10.1364/AO.55.000400

Wu Q, Wang J, Wang C, Xu T (2016) Study on the optimal algorithm prediction of corn leaf component information based on hyperspectral imaging. Infrared Physics and Technology 78:6-71. DOI: https://doi.org/10.1016/j.infrared.2016.07.011
Xiaobo Z, Jiyong S, Limin H, Jiewen Z, Hanpin M, Zhenwei C, Yanxiao L, Holmes M (2011) In vivo noninvasive detection of chlorophyll distribution in cucumber (Cucumis sativus) leaves by indices based on hyperspectral imaging. Analytica Chimica Acta 706(1):105112. DOI: https://doi.org/10.1016/j.aca.2011.08.026

Xiong D, Che J, Yu T, Gao W, Ling X, Li Y, Peng S, Huang J (2015) SPAD-based leaf nitrogen estimation is impacted by environmental factors and crop leaf characteristics. Scientific Reports 5:13389. DOI: https://doi.org/10.1038/srep13389.

Yang Y, Gao S, Jiang Y, Lin, Z, Luo J, Li M, Guo J, Su Y, Xu L, Que Y. (2019) The Physiological and Agronomic Responses to Nitrogen Dosage in Different Sugarcane Varieties. Frontiers Plant Science 10:406. DOI: https://doi.org/10.3389/fpls.2019.00406 